\title{
ABSTRAK \\ PENDAMPINGAN MELALUI MONITORING KETAT TERKAIT PENGATURAN DIET PADA PASIEN GAGAL GINJAL KRONIK YANG SEDANG MENJALANI HEMODIALISA
}

\author{
Safitri, Kiki Hardiansyah ${ }^{1}$, Sulistyarini, Wahyu Dewi ${ }^{2}$, Wulandari, Restu ${ }^{3}$, Ramadhani, Rezky ${ }^{4}$, Abdullah, Ririn \\ Saniah $^{5}$ \\ Program Studi Ilmu Keperawatan, Institut Teknologi Kesehatan dan Sains Wiyata Husada \\ Samarinda ${ }^{1,2,3,4,5}$ \\ *Korespondensi: kikihardiansyahsafitri@itkeswhs.ac.id,wahyudewis@itkeswhs.ac.id
}

Prevalensi dan insidens penyakit ginjal kronik (PGK) meningkat seiring bertambahnya kejadian penyakit diabetes melitus serta hipertensi. Penyakit ginjal kronik berpotensi menjadi kondisi yang terminal yang mengancam hidup. Intervensi keperawatan yang tepat berupa manajemen diri sangat diperlukan oleh pasien PGK yang menjalani hemodialisis untuk memelihara status kesehatannya. Manajemen diri (self-care management) adalah upaya untuk mempertahankan status kesehatan. Implementasi diet terapeutik merupakan upaya pelaksanaan diet oleh pasien PGK untuk berfungsi menjadi suatu terapi pada penyakitnya. Untuk memaksimalkan program diet yang dijalani oleh pasien PGK dan motivasi pasien dalam mengatur pola diet yang tepat dengan kondisi ini diperlukan adanya pendampingan monitoring pengaturan diet pada pasien gagal ginjal kronik. Kegiatan Pendidikan kesehatan (penyuluhan) kesehatan mengenai pola pengaturan diet dengan tepat dengan mengontrol komsumsi garam dan makanan lain yang aman dan sehat ini ditujukan pada pasien PGK yang ada di RS SMC. Sebanyak kurang lebih 20 peserta yang terlibat dalam kegiatan ini. Hasil proses monitoring diit selama $4 \mathrm{x}$ kunjungan rumah dan mengingatkan lewat telepon didapatkan hasil bahwa pasien optimal dalam pengaturan diet pada pasien gagal ginjal kronik dimana pada monitoring 1 yaitu sebanyak 8 pasien tidak sesuai anjuran, monitoring 2 yaitu sebanyak 4 pasien tidak sesuai anjuran dan monitoring 3 sebanyak 1 pasien tidak sesuai anjuran.

Kata kunci: Edukasi Kesehatan, Monitoring Diet, Gagal Ginjal Kronik, dan Hemodialisa.

\section{PENDAHULUAN}

Prevalensi dan insidens penyakit ginjal kronik (PGK) meningkat seiring bertambahnya kejadian penyakit diabetes melitus serta hipertensi. Kondisi tersebut dapat berkembang menjadi kegagalan ginjal yang menjadi masalah kesehatan dunia karena prognosis yang buruk dan biaya yang tinggi (RI, 2017). Sebuah studi metaanalysis dan systematic review memperlihatkan prevalensi PGK di dunia sebesar 13,4\% (Hill et al., 2016).

Peningkatan jumlah pasien PGK baru di Indonesia terus terjadi dari tahun ke tahun. Angka kejadian PGK baru di Indonesia sampai 2016 sebanyak 25.446 pasien, dan jumlah pasien aktif sebanyak 52.835 pasien (Registry, 2016). Proporsi terbanyak (90\%) pasien PGK adalah stadium 5 yaitu 22.170 pasien (Registry, 2016). Melonjaknya jumlah pasien PGK tahun 2016 menunjukkan peningkatan jumlah pasien PGK yang dapat menjalani hemodialisis lebih lama karena perolehan jaminan kesehatan nasional (Registry, 2016). Pembiayaan perawatan dan pengobatan PGK di Indonesia menduduki ranking kedua terbesar dari BPJS kesehatan setelah penyakit jantung (RI, 2017).

Penyakit ginjal kronik berpotensi menjadi kondisi yang terminal yang mengancam hidup. Kematian pasien PGK yang menjalani hemodialisa sebagian besar disebabkan adalah kardiovaskuler $41 \%$, dan penyebab lain kematian pasien PGK diluar rumah sakit yang tidak diketahui masih cukup besar yaitu sekitar 30\% (Registry, 2016). Lama harapan hidup pasien PGK hemodialisis bervariasi. Pasien PGK mengalami lama hidup sejak dimulainya hemodialisa selama kurang dari 3 bulan sebanyak 39,3\%, lama hidup 13-24 bulan sebanyak 16,8\%, lama hidup 7-12 bulan 
sebanyak 14,9\%, dan lama hidup 3-6 bulan sebanyak $12,7 \%$, lama hidup lebih dari 3 bulan sebanyak 9,8\%, dan 25-36 bulan sebanyak 6,6\% (Registry, 2016).

Intervensi keperawatan yang tepat berupa manajemen diri sangat diperlukan oleh pasien PGK yang menjalani hemodialisis untuk memelihara status kesehatannya. Manajemen diri (self-care management) adalah upaya untuk mempertahankan status kesehatan meliputi: kemampuan mengenal perubahan tubuh; mengevaluasi perubahan; dan mengambil keputusan yang tepat untuk penatalaksanaan; melaksanakan strategi pengobatan; dan mengevaluasi respon terhadap tindakan yang dilakukan (Alligood, 2010).

Adapun permasalahan mitra dinyatakan sebagai berikut:

1. Masih belum maksimal program diet yang dijalani oleh pasien PGK yang ada di RS SMC

2. Kurangnya motivasi pasien dalam mengatur pola diet yang tepat dengan kondisi mengalami penyakit gagal ginjal kronik

3. Kurangnya dukungan dari keluarga terkait pelaksanaan diet pada pasien gagal ginjal kronik

4. Belum adanya pendampingan langsung yang dilakukan tenaga kesehatan dalam melaksanakan pengaturan diet pada pasien gagal ginjal kronik

5. Sudah dilakukan pemberian informasi mengenai pengaturan diet oleh rumah sakit

6. Selalu diberikan motivasi oleh tenaga kesehatan terkait efek positif apabila mengikuti pengaturan diet yang sudah diajarkan

\section{METODE}

Kegiatan pengabdian kepada masyarakat ini berlokasi di rumah sakit samarinda medika citra dan dilakukan juga dirumah pasien dengan melakukan beberapa kali kunjungan kerumah dan menelpon pasien guna melakukan monitoring terkait diitnya, dilaksanakan pada bulan April 2019 sampai Mei 2019. Kegiatan yang dilaksanakan meliputi sosialisasi dan pendampingan monitoring pengaturan diet pada pasien gagal ginjal kronik.

Kegiatan Pendidikan kesehatan (penyuluhan) kesehatan mengenai pendampingan dan monitoring pengaturan diet ini ditujukan pada pasien di rumah sakit medika citra. Sebanyak kurang lebih 20 peserta yang terlibat dalam kegiatan ini.

\section{HASIL}

Hasil dari kegiatan pengabdian kepada masyarakat ini diantaranya adalah:

1. Pasien diberikan Pendidikan kesehatan (penyuluhan) mengenai "monitoring pengaturan diet "

2. Dari hasil penyuluhan, pasien sangat kooperatif dan antusias dan memahami mengenai isi materi dan di akhir sesi diberikan waktu tanya jawab.

3. Untuk mengevaluasi tingkat pemahaman pasien terhadap isi materi penyuluhan, maka diberikan beberapa pertanyaan terkait isi materi penyuluhan dan pasien dipersilahkan untuk menjawab. Warga yang berhasil menjawab pertanyaan dengan benar diberikan door prize sebagai tanda apresiasi.

Sedangkan outcome yang didapatkan diantaranya adalah:

1. Program pengabdian kepada masyarakat yang berupa pemeriksaan kesehatan, konseling dan penyuluhan kesehatan mengenai "pendampingan dan monitoring pengaturan diet" yang baik ini diharapkan dapat meningkatkan pengetahuan pasien tentang menjalankan pengaturan diet dengan cara mengontrol komsumsi garam dan makanan yang aman selama menjalani pengobatan dan 
hemodialisa serta keluarga memberikan dukungan yang penuh selama proses pengaturan diet pada pasien gagal ginjal kronik yang menjalani hemodialisa.

2. Program pengabdian kepada masyarakat lebih jauh diharapkan mampu memaksimalkan program diet yang dijalani oleh pasien PGK, dan memotivasi pasien dalam mengatur pola diet yang tepat.

3. STIKES Wiyata Husada Samarinda, khususnya Program Studi Ilmu Keperawatan semakin dikenal sebagai institusi yang mempunyai kepedulian terhadap permasalahan masyarakat.

Kegiatan pengabdian masyarakat dilakukan dalam pendampingan dan monitoring pada pasien gagal ginjal kronik yang menjalani hemodialisa di rumah sakit samarinda medika citra. Sasaran kegiatan adalah 20 orang. Bentuk kegiatan pengabdian masyarakat berupa pendampingan monitoring pengaturan diet pada pasien gagal ginjal kronik yang menjalani hemodialisa. Kegiatan pengabdian masyarakat dilakukan dalam pendampingan dan monitoring pada tanggal 23 April 2019 sampai 23 Mei 2019 dengan jumlah pasien dan keluarga 20 orang.

Sebelum kegiatan pendampingan dan monitoring dimulai dosen dan mahasiswa melakukan koordinasi dengan pihak rumah sakit samarinda medika citra berkaitan dengan teknis dilapangan serta memaparkan rencana kegiatan agar sesuai dengan rencana. Pihak rumah sakit beserta kepala ruangan turut serta membantu mempersiapkan tempat dan mempersiapkan alat yang akan digunakan pada saat acara pendampingan dan monitoring. Peserta monitoring merupakan pasien gagal ginjal kronik. Tempat yang digunakan dalam kegiatan ini adalah ruang hemodialisa dan rumah pasien.

Butir-butir pengaturan diet meliputi: asupan rendah garam, rendah gula, rendah lemak, hindari bahan penyedap makanan, menghindari kekenyangan, membatasi cairan. Makanan yang aman adalah salah satu elemen dari universal self-care yang terdiri: upaya memeriksa kandungan kalori, natrium, panel informasi nutrisi, tanggal produksi makanan, dan bahan buatan dalam makanan olahan. Makanan yang aman merupakan unsur selfcare yang penting bagi pasien PGK hemodialisis untuk mengendalikan tekanan darah sistolik dan diastolik, serta mempertahankan fungsi ginjal dengan menghindari komposisi dalam makanan yang dapat merusak ginjal.

Implementasi diet terapeutik merupakan upaya pelaksanaan diet oleh pasien PGK untuk berfungsi menjadi suatu terapi pada penyakitnya. Implementasi diet terapeutik meliputi: menjaga intake cairan sesuai rekomendasi dokter; menjaga intake garam dalam batas yang diresepkan dokter; menjaga makanan sesuai yang direkomendasikan dokter; mengkonsumsi buah sesuai advis dokter; menjaga kalori dalam batas yang diresepkan dokter; mengikuti diet yang ditentukan untuk perawatan hemodialisis; menjaga gula seminimal mungkin; dan mengkonsumsi makanan yang mengandung vitamin B dan C.

\section{KESIMPULAN}

Kurang optimal pengaturan diet pada pasien gagal ginjal kronik maka dilaksanakan upaya promotive dan preventif yang dilakukan oleh dosen dan mahasiwa keperawatan ITKes Wiyata Husada Samarinda, agar pasien gagal ginjal kronik yang menjalani hemodialisa bisa terkontrol berat badan dan kondisi kesehatannya. Selain itu, keluarga memahami dan memberikan dukungan kepada pasien gagal ginjal kronik yang sedang menjalani hemodialisa.

\section{REFERENSI}

Hill, N. R., Fatoba, S. T., Oke, J. L., Hirst, J. A., O'Callaghan, C. A., Lasserson, D. S., \& Hobbs, F. D. R. (2016). Global 
Prevalence of Chronic Kidney Disease A Systematic Review and Meta-Analysis. Plos One, 11(7), e0158765. doi:10.1371/journal.pone. 0158765

Palmer, S. C., Maggo, J. K., Campbell, K. L., Craig, J. C., Johnson, D. W., Sutanto, B., . . . Strippoli, G. F. (2017). Dietary interventions for adults with chronic kidney disease. Cochrane Database Syst Rev, 4(4), Cd011998. doi:10.1002/14651858.CD011998.pub2

Registry, T. I. R. (2016). 9th Report Of Indonesian Renal Registry 2016. 46. Retrieved from https://www.indonesianrenalregistry.org/\# $\mathrm{cmt3}$

RI, K. K. (2017). Infodatin Situasi Penyakit Ginjal Kronik. 10. Retrieved from https://pusdatin.kemkes.go.id/article/view /17050400001/situasi-penyakitginjalkronis.html

Sulastri, S., Nursalam, N., \& Astuti, P. (2018). Pengaruh Edukasi Self Care Berbasis Interaksi Perawat Pasien terhadap Kepatuhan Diet pada Pasien Penyakit Ginjal Kronik (Di Instlasi Rawat Jalan Rumah Sakit Islam Surabaya A. Yani). Jurnal Ilmiah Keperawatan (Scientific Journal of Nursing), 4(2), 77-82. doi:10.33023/jikep.v4i2.174

Tumini, D. W. D. (2017). Self Care Management Pasien Hemodialisa Ditinjau dari Dukungan Keluarga di RSUD Dr Soetomo Surabaya. Jurnal Ilmu Kesehatan, 6(1), 9. 